\title{
Air pollution exposure estimation using dispersion modelling and continuous monitoring data in a prospective birth cohort study in the Netherlands
}

\author{
Edith H Van den Hooven ${ }^{1,2,3^{*}}$, Frank H Pierik², Sjoerd W Van Ratingen², Peter YJ Zandveld², Ernst W Meijer ${ }^{2}$, \\ Albert Hofman ${ }^{3}$, Henk ME Miedema ${ }^{2}$, Vincent WV Jaddoe ${ }^{1,3,4}$ and Yvonne De Kluizenaar ${ }^{2}$
}

\begin{abstract}
Previous studies suggest that pregnant women and children are particularly vulnerable to the adverse effects of air pollution. A prospective cohort study in pregnant women and their children enables identification of the specific effects and critical periods. This paper describes the design of air pollution exposure assessment for participants of the Generation R Study, a population-based prospective cohort study from early pregnancy onwards in 9778 women in the Netherlands. Individual exposures to $\mathrm{PM}_{10}$ and $\mathrm{NO}_{2}$ levels at the home address were estimated for mothers and children, using a combination of advanced dispersion modelling and continuous monitoring data, taking into account the spatial and temporal variation in air pollution concentrations. Full residential history was considered. We observed substantial spatial and temporal variation in air pollution exposure levels. The Generation R Study provides unique possibilities to examine effects of short- and long-term air pollution exposure on various maternal and childhood outcomes and to identify potential critical windows of exposure.
\end{abstract}

Keywords: Air pollution, Dispersion modelling, Particulate matter, Nitrogen dioxide, Cohort study, Pregnant women, Prenatal development, Child health

\section{Background}

Air pollution exposure has been associated with several adverse health effects, such as cardiovascular disease, respiratory disease, and total mortality [1-4]. Certain subgroups of the population, including pregnant women and their unborn children, have been suggested to be more susceptible to the adverse effects of air pollution $[5,6]$. Literature on the specific effects of air pollution exposure in pregnant women on outcomes such as inflammation markers, placental function, and blood pressure, is scarce. In contrast, research on the impact of air pollution exposure on birth outcomes has increased in the last decade, which has led to a number of reviews summarizing the available evidence $[7,8]$. Most routinely measured air pollutants (e.g., $\mathrm{PM}_{10}, \mathrm{NO}_{2}, \mathrm{CO}, \mathrm{O}_{3}, \mathrm{SO}_{2}$ ) have been linked

\footnotetext{
* Correspondence: e.vandenhooven@erasmusmc.nl

'The Generation R Study Group, Erasmus Medical Center, Rotterdam, The Netherlands

Full list of author information is available at the end of the article
}

to increased risks of adverse birth outcomes [6]. However, results are not consistent between studies, with respect to the specific air pollutants, the relevant exposure periods, and the specific birth outcomes $[7,8]$. Recommendations for future research are to improve exposure assessment by incorporating detailed information on spatial and temporal patterns in air pollution concentrations and to consider a greater variety of reproductive outcomes [9]. Furthermore, it is of interest to include noise exposure data in studies on traffic-related air pollution exposure and health, since traffic is a major shared source for both air pollution and noise [10-13].

Dispersion models are applied to estimate air pollution concentrations in a study area, using data on emissions, meteorological conditions, and topography [14]. Despite the relatively costly data input, dispersion modelling is a promising method to obtain air pollution estimates for epidemiological studies, as it allows consideration of both spatial and temporal variation without the need for

\section{(Ciomed Central}


extensive air pollution monitoring. Dispersion models are increasingly used in combination with geographic information system (GIS) based methods. This introduces the possibility for spatial linkage of geographically referenced data, such as residential addresses, road networks, pollution sources, and street characteristics, which further enhances the quality of the modelling approach $[14,15]$.

In this paper we describe the design of studies focused on the effects of air pollution exposure on various health outcomes in mothers and children in the Generation $\mathrm{R}$ Study. We describe the assessment of individual exposures to particulate matter $\left(\mathrm{PM}_{10}\right)$ and nitrogen dioxide $\left(\mathrm{NO}_{2}\right)$ at the home address, using a combination of continuous monitoring data and GIS based dispersion modelling techniques, taking into account both the spatial and temporal variation in air pollution. In addition, we present the distribution of exposure levels for various relevant exposure periods in the prenatal and postnatal phase, and we present exposure levels according to maternal and infant characteristics.

\section{Methods}

\section{Study design}

The Generation R Study is a population-based prospective cohort study from pregnancy onwards, which was designed to identify early environmental and genetic causes of normal and abnormal growth, development, and health during fetal life, childhood and adulthood. It has been described previously in detail $[16,17]$. In brief, the cohort includes mothers and children of different ethnicities living in the city of Rotterdam, the Netherlands. Enrolment was aimed in early pregnancy (gestational age $<18$ weeks), but was allowed until the birth of the child. Out of the total number of eligible children in the study area, 61 percent participated in the study at birth. In total, 9778 mothers with a delivery date between April 2002 and January 2006 were enrolled in the study. Extensive assessments have been carried out in mothers and fathers and are currently performed in their children, who form a prenatally recruited birth cohort that will be followed until young adulthood. Data collection included questionnaires, detailed physical and ultrasound examinations, behavioural observations, and biological samples. Assessments in pregnancy were performed in each trimester. Assessments in the children in the preschool period (birth to age of 4 years) included a home-visit, questionnaires, and visits to the routine child health centres. From the age of 5 years onward, regular detailed hands on assessments are performed in all children and their parents in a research center. The study protocol was approved by the Medical Ethical Committee of Erasmus Medical Center, Rotterdam. Written informed consent was obtained from all participants.

\section{Air pollution exposure assessment}

Individual exposures to $\mathrm{PM}_{10}$ and $\mathrm{NO}_{2}$ levels during pregnancy were assessed at the home address, using advanced spatiotemporal dispersion modelling techniques in combination with hourly air pollution measurements at three continuous monitoring sites. The exposure assessment procedure has been described previously $[18,19]$. Below, we give a brief summary of the procedure, including some revised information that better describes the individual steps.

\section{Spatial pattern}

Annual average concentrations of $\mathrm{PM}_{10}$ and $\mathrm{NO}_{2}$ for the years 2001-2008 were assessed for all addresses in the study area, using GIS and the three Dutch national standard methods for air quality modelling (considering intra-urban road traffic, traffic on highways, and industrial and other point sources) [20]. Subsequently, in order to obtain spatiotemporal patterns, spatially resolved annual concentrations were calculated for eight different wind conditions, resulting in an averaged spatially resolved concentration pattern for each wind class. Various input data was taken into account in the calculations as described earlier $[18,19]$, including annual data on traffic intensities and annual emissions from traffic, shipping, industry, and households. The traffic intensity data was supplied by the DCMR Environmental Protection Agency Rijnmond (DCMR), and emission sources and emission data were obtained from the National Institute for Public Health and the Environment (RIVM) and the DCMR. Hourly meteorological data was obtained from observations at Rotterdam The Hague Airport, performed by the Royal Netherlands Meteorological Institute (KNMI).

\section{Temporal pattern}

To account for temporal variation due to different wind conditions, for each hour we derived the corresponding spatial distribution for the prevailing wind direction and wind speed at that specific hour, by means of interpolation between the eight characteristic spatial distributions. Subsequently, the spatial distributions that corresponded to the hourly wind conditions were adjusted for fixed temporal patterns of source activities. In this way, we accounted for temporal fluctuations in the contribution of air pollution sources during the month, week (e.g., working days and weekend days), and day (e.g., morning and evening rush hour). The adjustment for temporal patterns was performed for traffic and for household emissions. Traffic is the source with the strongest fluctuations in emissions within 24 hours. This 24 h-pattern is fairly stable for working days and weekend days. Hence, the contribution of traffic was scaled using an average hourly traffic intensity pattern (based on traffic counts), thereby deriving hourly intensities. We also 
considered the time dependence of household emissions, by applying a $24 \mathrm{~h}$-pattern, and we applied a function for outdoor temperature dependence to account for seasonal fluctuations. These functions were derived from energy use statistics. In this way, hourly household emissions were estimated from annual household emissions. Emissions from industrial sources do not contribute significantly to small-scale variations in air pollution concentrations. Emissions from shipping are quite stable over time and also display relatively small temporal fluctuations. Therefore, these emissions were not adjusted for fixed temporal patterns. Nevertheless, even if some small-scale variations had occurred as a result of these emissions, the difference would have been corrected for in the next step (adjustment for hourly background concentrations).

\section{Adjustment for background concentrations}

The modelled hourly concentrations were adjusted for background concentrations (see also $[18,19]$ ), in order to consider the temporal fluctuations in background concentrations. This was done using continuous hourly monitoring data from three monitoring stations in the study area. The measured air pollution concentrations at these stations are considered as the sum of the background concentration and the contribution from local emission sources. We modelled the contribution of local emission sources to the $\mathrm{PM}_{10}$ and $\mathrm{NO}_{2}$ concentrations at the three monitoring stations. Subsequently, we subtracted the hourly modelled contributions from the hourly measured concentrations at the stations, thereby deriving an hourly estimate for the background concentrations. The hourly estimates for the background concentrations at the three stations were averaged, which yielded an average hourly background concentration for the study area. In the adjustment procedure, this average hourly background concentration was added to the modelled hourly contributions at the home addresses, in order to take into account the background concentration.

Continuous air pollution monitoring data was provided by DCMR. Missing values for $\mathrm{PM}_{10}$ concentrations at the three monitoring stations were imputed, as described earlier $[18,19]$.

\section{Modelling performance}

As described above, the first step in our modelling procedure involved the assessment of annual average $\mathrm{PM}_{10}$ and $\mathrm{NO}_{2}$ concentrations, using a combination of the three Dutch standard methods. The performance of this modelling procedure based on (a combination of) the three standard methods has been evaluated by two previous studies in the same study area. These studies reported a good agreement between predicted annual average $\mathrm{PM}_{10}$ and $\mathrm{NO}_{2}$ concentrations and concentrations measured at monitoring stations $[21,22]$. Our dispersion modelling approach, resulting in hourly average concentrations, is a refinement of this former modelling procedure. An additional validation study of this refined modelling procedure was not feasible within the scope of this project.

\section{Exposure assignment}

Derived from the hourly concentrations of $\mathrm{PM}_{10}$ and $\mathrm{NO}_{2}$, we constructed a database containing daily averages $(24 \mathrm{~h})$ for every address, for the years 2001-2008. Allowing for residential mobility, air pollution exposure estimates were linked to the different home addresses of the participants throughout the study period. This yields a database with individual exposures, which can be used to derive average exposure estimates for any period between 2001 and 2008, depending on the specific research question. For the present paper, we describe air pollution exposure estimates for a number of pregnancy and childhood periods, to illustrate the distribution of exposure levels in participants in these potential sensitive periods. More specifically, we derived exposures for the following periods: first trimester, second trimester, third trimester, total pregnancy, birth until 6 months postnatally, and 7 until 12 months postnatally. Exposures were only calculated for periods with less than $25 \%$ of the daily averages missing. For the other periods, air pollution exposures were set to missing.

\section{Statistical analyses}

Descriptive analyses were performed for all air pollution exposure averages, including the evaluation of the Pearson correlation coefficients between the different exposure averages. In addition, we examined mean maternal $\mathrm{PM}_{10}$ and $\mathrm{NO}_{2}$ exposure levels during total pregnancy according to maternal characteristics and infant characteristics. Information on these characteristics was obtained from questionnaires in pregnancy and from medical records, as described elsewhere [16,18]. Maternal noise exposure (based on the home address at time of delivery) was assessed in accordance with requirements of the EU Environmental Noise Directive, which has been described previously $[10,16,18,23]$. Information on average neigbourhood income was obtained from Statistics Netherlands as neighbourhoods' average disposable income per income receiver in the year 2004, and classified into: low (< 1400 euro/month), moderate (1400-2200 euro/month), and high (> 2200 euro/month). Season of conception and season of birth were categorized as winter (December to February), spring (March to May), summer (June to August), and fall (September to November). For all maternal and infant characteristics, we performed a one-way ANOVA followed by Bonferroni's post hoc comparison tests to examine the differences in mean air pollution exposure levels compared with the reference group. All statistical analyses were performed using PASW version 17.0 for Windows (PASW Inc., Chicago, IL). 


\section{Results}

\section{Air pollution exposure in the study cohort}

Of the 9778 women, exposure estimates could not be calculated for 149 mothers because they had an abortion ( $n=29)$ or intrauterine death $(n=75)$, or were lost-tofollow up ( $\mathrm{n}=45)$, and consequently no information was available on the date of conception and delivery. For the remaining 9629 women (and their 9748 children), 12188 addresses were available for the time period presented here (conception until the first year postnatally). Of all women, $74 \%$ did not move in this period, $25 \%$ changed residence once, and less than $1 \%$ moved two or three times. Of the 12188 addresses, 10518 (86\%) could be linked to the air pollution exposure database, and 1938 addresses could not be linked. This was either due to missing address information, incompatible street number suffices, or to addresses situated outside of the study area of the Generation R Study [16]. As a result, air pollution exposure estimates for the present paper were available for 8810 mothers and 8921 children.

Table 1 presents the distribution of maternal $\mathrm{PM}_{10}$ and $\mathrm{NO}_{2}$ levels for a number of illustrative prenatal and postnatal periods. The number of participants with available exposure data varied for the specific periods. On average, $\mathrm{PM}_{10}$ and $\mathrm{NO}_{2}$ exposure levels during first trimester were higher than during second and third trimester, and postnatal exposure levels were lower than prenatal exposure levels. This can be explained by the decreasing trend in air pollution levels throughout the study period. Mean air pollution exposure levels during pregnancy were $30.2 \mu \mathrm{g} / \mathrm{m}^{3}$ (range 23.1 to 39.9 ) for $\mathrm{PM}_{10}$ and $39.7 \mu \mathrm{g} / \mathrm{m}^{3}$ (range 25.3 to 56.9 ) for $\mathrm{NO}_{2}$ (Table 1). On average, these levels are below the European Union annual limit values $\left(40 \mu \mathrm{g} / \mathrm{m}^{3}\right.$ for both $\mathrm{PM}_{10}$ and $\mathrm{NO}_{2}$ ) that are defined for protection of human health [24], but a substantial proportion of the women was exposed to levels higher than these limit values. Moreover, it has been acknowledged that significant health effects may occur even below the current limit values [25].

Epidemiological studies often evaluate associations for air pollution exposure levels in different periods, in order to examine the relevant exposure periods, which is informative only if the correlations among these exposure levels are not too high. Table 2 shows that Pearson correlation coefficients between the different air pollution exposure averages for the present paper varied between 0.02 and 0.83 . Correlations among exposure averages for the first, second, and third trimester were moderate $\left(\mathrm{PM}_{10}: \mathrm{r}=0.31\right.$ to $0.48, \mathrm{NO}_{2}: \mathrm{r}=0.17$ to 0.48$)$. Correlations between exposure averages for the separate trimesters with exposure averages for the total pregnancy period were higher $\left(\mathrm{PM}_{10}: \mathrm{r}=0.73\right.$ to $0.83, \mathrm{NO} 2: \mathrm{r}=0.43$ to 0.51$)$. Correlations between prenatal and postnatal exposure averages were low for $\mathrm{PM}_{10}(\mathrm{r}=0.13$ to 0.29$)$, and somewhat higher for $\mathrm{NO}_{2}(\mathrm{r}=0.22$ to 0.78$) . \mathrm{PM}_{10}$ and $\mathrm{NO}_{2}$ exposures averages for the same period were moderately correlated ( $\mathrm{r}=0.58$ to 0.66 ).

There was substantial spatial and temporal variation in air pollution exposure levels. We have previously published

Table 1 Distribution of maternal $\mathrm{PM}_{10}$ and $\mathrm{NO}_{2}$ exposure levels for different prenatal and postnatal periods

\begin{tabular}{|c|c|c|c|c|c|c|c|}
\hline & $\mathrm{N}$ & Minimum & 25th percentile & Mean & Median & 75th percentile & Maximum \\
\hline \multicolumn{8}{|l|}{$\mathrm{PM}_{10}$ exposure $\left(\mu \mathrm{g} / \mathrm{m}^{3}\right)$} \\
\hline \multicolumn{8}{|l|}{ Prenatal } \\
\hline First trimester & 7894 & 22.0 & 27.7 & 30.6 & 30.5 & 33.4 & 43.1 \\
\hline Second trimester & 8311 & 21.3 & 26.2 & 30.1 & 29.5 & 33.3 & 45.6 \\
\hline Third trimester & 8438 & 22.0 & 26.6 & 29.8 & 29.8 & 32.0 & 43.5 \\
\hline Total pregnancy & 7877 & 23.1 & 27.7 & 30.2 & 29.9 & 32.8 & 39.9 \\
\hline \multicolumn{8}{|l|}{ Postnatal } \\
\hline Month 0-6 & 8381 & 22.7 & 27.3 & 29.5 & 29.3 & 31.4 & 39.9 \\
\hline Month 7-12 & 8082 & 22.8 & 27.0 & 28.8 & 28.7 & 30.5 & 39.3 \\
\hline \multicolumn{8}{|l|}{$\mathrm{NO}_{2}$ exposure $\left(\mu \mathrm{g} / \mathrm{m}^{3}\right)$} \\
\hline \multicolumn{8}{|l|}{ Prenatal } \\
\hline First trimester & 7893 & 21.4 & 36.9 & 40.2 & 40.6 & 43.5 & 58.5 \\
\hline Second trimester & 8310 & 20.2 & 35.2 & 39.6 & 40.5 & 43.9 & 59.7 \\
\hline Third trimester & 8434 & 21.3 & 35.4 & 39.3 & 39.9 & 43.2 & 58.8 \\
\hline Total pregnancy & 7889 & 25.3 & 37.0 & 39.7 & 39.5 & 42.2 & 56.9 \\
\hline \multicolumn{8}{|l|}{ Postnatal } \\
\hline Month 0-6 & 8389 & 24.2 & 36.3 & 39.4 & 39.5 & 42.5 & 59.3 \\
\hline Month 7-12 & 8082 & 24.1 & 35.5 & 38.6 & 38.6 & 41.6 & 58.0 \\
\hline
\end{tabular}

Air pollution exposure was estimated for different prenatal and postnatal periods: first trimester (0-18 weeks), second trimester (18-25 weeks), third trimester (25 weeks-delivery), total pregnancy, month 0-6 postnatally, and month 7-12 postnatally 
Table 2 Correlation coefficients between period-specific $\mathrm{PM}_{10}$ and $\mathrm{NO}_{2}$ exposure averages

\begin{tabular}{|c|c|c|c|c|c|c|c|c|c|c|c|c|}
\hline & $\mathrm{PM}_{10}$ & & & & & & & & $\mathrm{NO}_{2}$ & & & \\
\hline & $\begin{array}{l}\text { First } \\
\text { trimester }\end{array}$ & $\begin{array}{l}\text { Second } \\
\text { trimester }\end{array}$ & $\begin{array}{l}\text { Third } \\
\text { trimester }\end{array}$ & $\begin{array}{l}\text { Total } \\
\text { pregnancy }\end{array}$ & $\begin{array}{l}\text { Month0-6 } \\
\text { postnatally }\end{array}$ & $\begin{array}{l}\text { Month 7-12 } \\
\text { postnatally }\end{array}$ & $\begin{array}{l}\text { First } \\
\text { trimester }\end{array}$ & $\begin{array}{l}\text { Second } \\
\text { trimester }\end{array}$ & $\begin{array}{l}\text { Third } \\
\text { trimester }\end{array}$ & $\begin{array}{l}\text { Total } \\
\text { pregna ncy }\end{array}$ & $\begin{array}{l}\text { Month } 0-6 \\
\text { postnatally }\end{array}$ & $\begin{array}{l}\text { Month 7-12 } \\
\text { postnatally }\end{array}$ \\
\hline \multicolumn{13}{|l|}{$\mathrm{PM}_{10}$} \\
\hline First trimester & 1 & & & & & & & & & & & \\
\hline $\begin{array}{l}\text { Second } \\
\text { trimester }\end{array}$ & 0.48 & 1 & & & & & & & & & & \\
\hline Third trimester & 0.31 & 0.46 & 1 & & & & & & & & & \\
\hline $\begin{array}{l}\text { Total } \\
\text { pregnancy }\end{array}$ & 0.83 & 0.74 & 0.73 & 1 & & & & & & & & \\
\hline $\begin{array}{l}\text { Month 0-6 } \\
\text { postnatally }\end{array}$ & 0.19 & 0.13 & 0.34 & 0.29 & 1 & & & & & & & \\
\hline $\begin{array}{l}\text { Month 7-12 } \\
\text { postnatally }\end{array}$ & 0.11 & 0.02 & 0.01 & 0.06 & 0.21 & 1 & & & & & & \\
\hline \multicolumn{13}{|l|}{$\mathrm{NO}_{2}$} \\
\hline First trimester & 0.59 & 0.36 & 0.19 & 0.51 & 0.28 & 0.01 & 1 & & & & & \\
\hline $\begin{array}{l}\text { Second } \\
\text { trimester }\end{array}$ & 0.26 & 0.58 & 0.41 & 0.48 & 0.15 & 0.24 & 0.45 & 1 & & & & \\
\hline Third trimester & 0.17 & 0.24 & 0.63 & 0.43 & 0.25 & 0.36 & 0.17 & 0.48 & 1 & & & \\
\hline $\begin{array}{l}\text { Total } \\
\text { pregnancy }\end{array}$ & 0.49 & 0.47 & 0.53 & 0.64 & 0.32 & 0.26 & 0.77 & 0.76 & 0.73 & 1 & & \\
\hline $\begin{array}{l}\text { Month 0-6 } \\
\text { postnatally }\end{array}$ & 0.48 & 0.21 & 0.22 & 0.42 & 0.66 & 0.27 & 0.66 & 0.22 & 0.30 & 0.57 & 1 & \\
\hline $\begin{array}{l}\text { Month 7-12 } \\
\text { postnatally }\end{array}$ & 0.17 & 0.29 & 0.44 & 0.37 & 0.26 & 0.63 & 0.34 & 0.68 & 0.78 & 0.77 & 0.39 & 1 \\
\hline
\end{tabular}

Values reflect Pearson correlation coefficients between air pollution exposure estimates for different prenatal and postnatal periods 
maps of the spatial distribution of annual $\mathrm{PM}_{10}$ and $\mathrm{NO}_{2}$ concentrations in the study area $[18,19]$, which demonstrated differences in annual average concentrations up to 4- $8 \mu \mathrm{g} / \mathrm{m}^{3}$ between urban and suburban areas. Figure 1 presents the temporal variation in $\mathrm{PM}_{10}$ and $\mathrm{NO}_{2}$ exposure levels estimated at two different locations in the study area (one situated in the city center and one situated in a suburb of Rotterdam). Especially for $\mathrm{NO}_{2}$, substantial differences were observed between the two locations.

For illustrative purposes, we present mean maternal air pollution exposure during total pregnancy according to maternal characteristics (Table 3) and infant characteristics (Table 4). Table 3 shows that $\mathrm{PM}_{10}$ and $\mathrm{NO}_{2}$ exposure levels were higher for mothers who were younger than 25 years, of non-Dutch ethnicity, nulliparous, were exposed to higher noise levels, lived in a low neighbourhood income area, and whose conception occurred in summer or fall. In addition, $\mathrm{NO}_{2}$ exposure was slightly higher in women who continued smoking, and $\mathrm{PM}_{10}$ exposure was higher in women who continued to consume alcohol during pregnancy. There was a clear decrease in air pollution exposure over time: women whose conception fell between 2001 and 2003 were exposed to higher $\mathrm{PM}_{10}$ and $\mathrm{NO}_{2}$ levels during pregnancy than women with a conception date in 2004 or 2005. Table 4 shows that mothers were exposed to higher $\mathrm{PM}_{10}$ and $\mathrm{NO}_{2}$ levels when they gave birth in spring or summer, compared with winter or fall. Mean exposure levels according to the year of birth also showed a decreasing trend in air pollution concentrations between 2002 and 2006.

\section{Discussion}

For the participants of this large population-based cohort study, we assessed individual air pollution exposure at the home address using advanced state-of-theart methods. By using a combination of GIS based dispersion modelling and continuous monitoring data, we were able to take into account the spatial and temporal variation in air pollution concentrations. The individual exposure estimates can be used in further epidemiological studies that examine air pollution effects in this population of mothers and children.

\section{Air pollution exposure}

In our air pollution exposure assessment procedure, we were able to consider fine spatial and temporal contrasts in exposure by using a combination of dispersion modelling and continuous monitoring. The high temporal resolution enables investigation of relatively short exposure windows (e.g., total pregnancy, trimesters, or months) that are particularly of interest in pregnant women and children. It also facilitates identification of critical windows of exposure. These short-term exposure windows cannot be examined in studies with only annual average concentrations. In examination of the different exposure windows, the (possibly) moderate to high correlations among some of the exposure averages need to be considered when interpreting the results. Next to a high temporal resolution, detailed information on spatial contrasts in air pollution exposure is required, since ambient air pollutants display significant smallscale spatial variation. This intra-urban spatial variation has been documented especially for traffic-related pollutants such as $\mathrm{NO}_{2}$, black smoke, elemental carbon, ultrafine particles, and to a lesser extent for $\mathrm{PM}_{10}$ and $\mathrm{PM}_{2.5}[26,27]$. Our exposure estimates have been used in three previous studies on air pollution effects in the same population, which suggest that exposure to air pollution during pregnancy may affect maternal and fetal health $[18,19,28]$.

We explored whether air pollution exposure levels were differentially distributed according to maternal and infant characteristics. Associations between air pollution exposure and health may be subject to confounding, if sociodemographic and lifestyle-related factors are associated both with air pollution exposure and with health. Our illustrative findings suggest that in our cohort, air pollution exposure may be differentially distributed according to age, ethnicity, parity, neighbourhood income area, smoking, and alcohol consumption. This stresses the importance to account for these factors when analyzing the associations between air pollution exposure and health.

Rotterdam is the second largest city in the Netherlands with a high population density and the largest port of Europe. It is characterized by high emissions from road traffic, shipping, households, and industry. A few recent European studies assessed air pollution exposure in pregnant women using land-use regression modelling approaches that also considered spatiotemporal variation in exposure [29-32]. In these studies, mean $\mathrm{NO}_{2}$ exposure levels estimated for the entire pregnancy were slightly lower than those obtained in our cohort (i. e., around $36-37 \mu \mathrm{g} / \mathrm{m}^{3}$ compared with $40 \mu \mathrm{g} / \mathrm{m}^{3}$ in our cohort). None of the studies assessed $\mathrm{PM}_{10}$ exposure. The differences in exposure levels can be explained by various factors, including the geographic location and urbanization degree of the study area, study period (season and year), modelling approach input data, climate, meteorological conditions, and pollution sources.

Traffic-related air pollution is a complex mixture of several pollutants. We assessed exposure to $\mathrm{PM}_{10}$ and $\mathrm{NO}_{2}$ in our cohort, because these pollutants have been routinely measured in the National Air Quality Monitoring Network during the study period, and they often exceed the air quality standards at locations near heavy traffic. Furthermore, $\mathrm{PM}_{10}$ and $\mathrm{NO}_{2}$ can be regarded as 

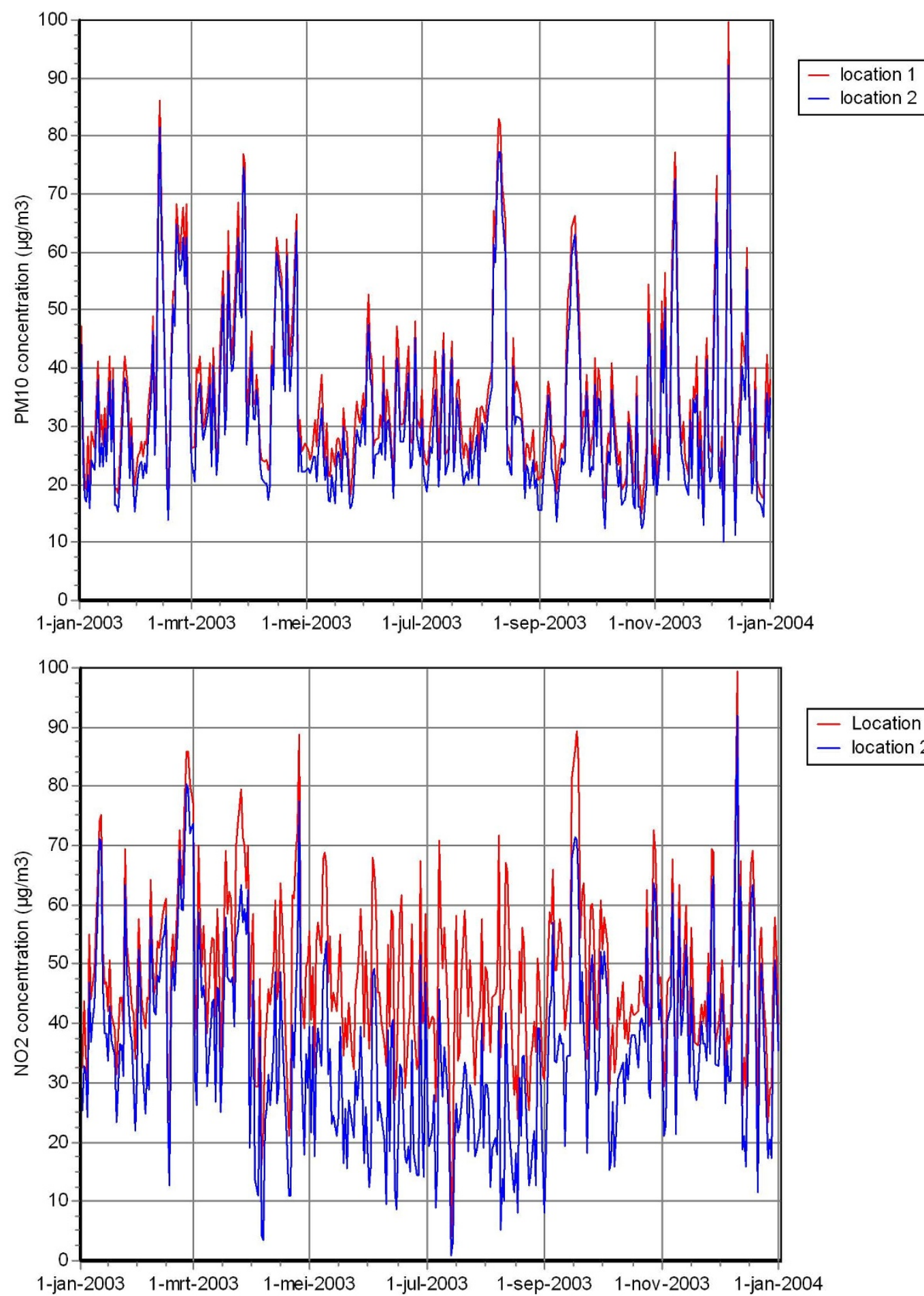

Figure 1 Illustration of the temporal variation in of $\mathbf{P M}_{10}$ and $\mathbf{N O}_{2}$ exposure levels in the study area. a. $\mathrm{PM} \mathrm{M}_{10} \mathrm{Concentration.} \mathrm{b.} \mathrm{NO}_{2}$ concentration. Estimated $\mathrm{PM}_{10}$ and $\mathrm{NO}_{2}$ concentrations in 2003 at two different locations in the study area. Location 1 is located in the city center, whereas location 2 is situated in a suburb of Rotterdam.

markers for the traffic-related air pollution mixture and have been associated with several adverse health effects [1,2,9,33-35]. Other components that may be relevant for health $\left(\mathrm{PM}_{2.5}\right.$, black smoke) have not been monitored during the study period and could therefore not be assessed. Up to now, we have assessed air pollution 
Table 3 Maternal air pollution exposure during pregnancy according to maternal characteristics

\begin{tabular}{|c|c|c|c|}
\hline & $\mathrm{N}$ & $\mathrm{PM}_{10}$ exposure $\left(\mu \mathrm{g} / \mathrm{m}^{3}\right)$ Mean (SD) & $\mathrm{NO}_{2}$ exposure $\left(\mu \mathrm{g} / \mathrm{m}^{3}\right)$ Mean (SD) \\
\hline \multicolumn{4}{|l|}{ Maternal characteristics } \\
\hline \multicolumn{4}{|l|}{ Age } \\
\hline$<25$ years & 1446 & $30.5(3.2) *$ & $40.4(3.8) *$ \\
\hline 25-30 years (Reference) & 2051 & $30.2(3.1)$ & $39.8(4.2)$ \\
\hline $30-35$ years & 2998 & $30.1(3.2)$ & $39.5(4.4) *$ \\
\hline$>35$ years & 1395 & $30.0(3.2)$ & $39.5(4.3)$ \\
\hline \multicolumn{4}{|l|}{ Body mass index } \\
\hline$<20 \mathrm{~kg} / \mathrm{m}^{2}$ & 627 & $30.5(3.2)$ & $40.3(4.2)$ \\
\hline $20-25 \mathrm{~kg} / \mathrm{m}^{2}$ (Reference) & 3714 & $30.3(3.2)$ & $39.8(4.2)$ \\
\hline $25-30 \mathrm{~kg} / \mathrm{m}^{2}$ & 1843 & $30.3(3.1)$ & $39.8(4.1)$ \\
\hline$>30 \mathrm{~kg} / \mathrm{m}^{2}$ & 972 & $30.0(3.2)$ & $39.6(4.0)$ \\
\hline Missing & 734 & $29.1(3.1)^{* *}$ & $38.6(4.7) * *$ \\
\hline \multicolumn{4}{|l|}{ Ethnicity } \\
\hline Dutch/Caucasian (Reference) & 4268 & $30.1(3.2)$ & $39.4(4.5)$ \\
\hline Turkish & 622 & $30.1(3.0)$ & $40.2(3.5) * *$ \\
\hline Moroccan & 489 & $30.2(3.0)$ & $40.1(3.5) *$ \\
\hline Surinamese & 619 & $30.6(3.2) *$ & $40.2(4.0) * *$ \\
\hline Other & 1151 & $30.4(3.3) *$ & $40.3(4.1) * *$ \\
\hline Missing & 741 & $29.8(3.0)$ & $40.1(4.0) * *$ \\
\hline \multicolumn{4}{|l|}{ Educational level } \\
\hline No education/primary & 757 & $30.3(3.1)$ & $40.0(3.6)$ \\
\hline Secondary & 3102 & $30.3(3.2)$ & $39.7(4.3)$ \\
\hline Higher (Reference) & 3132 & $30.1(3.2)$ & $39.6(4.4)$ \\
\hline Missing & 899 & $29.8(3.0)$ & $40.1(4.0) *$ \\
\hline \multicolumn{4}{|l|}{ Parity } \\
\hline Nulliparous (Reference) & 4129 & $30.3(3.2)$ & $40.0(4.3)$ \\
\hline Multiparous & 3528 & $30.1(3.1) *$ & $39.5(4.1) * *$ \\
\hline Missing & 233 & $29.4(3.1) * *$ & $38.8(4.5) * *$ \\
\hline \multicolumn{4}{|l|}{ Smoking in pregnancy } \\
\hline No (Reference) & 4616 & $30.2(3.2)$ & $39.7(4.2)$ \\
\hline First trimester only & 527 & $30.5(3.3)$ & $40.1(4.6)$ \\
\hline Continued & 1059 & $30.5(3.2)$ & $40.2(4.2) *$ \\
\hline Missing & 1688 & $29.6(2.9) * *$ & $39.5(4.2)$ \\
\hline \multicolumn{4}{|l|}{ Alcohol use in pregnancy } \\
\hline No (Reference) & 3022 & $30.2(3.2)$ & $39.8(4.1)$ \\
\hline First trimester only & 820 & $30.2(3.2)$ & $39.6(4.4)$ \\
\hline Continued & 2415 & $30.4(3.2) *$ & $39.9(4.3)$ \\
\hline Missing & 1633 & $29.7(2.9) * *$ & $39.5(4.2)$ \\
\hline \multicolumn{4}{|l|}{ Noise exposure } \\
\hline$<50 \mathrm{~dB}(\mathrm{~A})$ & 2985 & $29.6(3.0) * *$ & $37.9(3.3) * *$ \\
\hline 50-65 $d B(A)$ (Reference) & 4016 & $30.2(3.1)$ & $39.8(3.6)$ \\
\hline$>65 \mathrm{~dB}(\mathrm{~A})$ & 791 & $32.2(3.5) * *$ & $46.0(4.3) * *$ \\
\hline Missing & 91 & $29.8(3.1)$ & $40.0(4.0)$ \\
\hline \multicolumn{4}{|l|}{ Neighbourhood income } \\
\hline Low & 1141 & $30.9(2.9) * *$ & $41.0(3.2) * *$ \\
\hline Moderate (Reference) & 4678 & $30.0(3.1)$ & $39.6(4.2)$ \\
\hline High & 1945 & $30.2(3.2)$ & $39.6(4.5)$ \\
\hline
\end{tabular}


Table 3 Maternal air pollution exposure during pregnancy according to maternal characteristics (Continued)

\begin{tabular}{llll}
\hline Missing & 126 & $28.4(3.2)^{* *}$ & $35.2(5.5)^{* *}$ \\
\hline Season of conception & & & $38.8(4.5)$ \\
\hline Winter (Reference) & 2184 & $29.9(3.8)$ & $38.9(4.1)$ \\
\hline Spring & 1850 & $29.7(2.6)$ & $41.1(3.8)^{* *}$ \\
\hline Summer & 1810 & $30.5(2.4)^{* *}$ & $40.3(3.9)^{* *}$ \\
\hline Fall & 2046 & $30.5(3.4)^{* *}$ & $39.6(3.4)$ \\
\hline Year of conception & & & $41.8(3.8)$ \\
\hline 2001 (Reference) & 345 & $34.6(1.3)$ & $39.9(4.2)^{* *}$ \\
\hline 2002 & 2161 & $33.1(1.6)^{* *}$ & $38.2(3.9)^{* *}$ \\
\hline 2003 & 2468 & $29.5(3.0)^{* *}$ & $37.4(4.1)^{* *}$ \\
\hline 2004 & 2460 & $28.0(2.0)^{* *}$ & $28.4(1.2)^{* *}$ \\
\hline
\end{tabular}

** $P<0.01$

* $P<0.05$

Values are mean $\mathrm{PM}_{10}$ and $\mathrm{NO}_{2}$ exposure levels for the total pregnancy period. $P$-values are based on One-way ANOVA followed by Bonferroni's post hoc comparison tests to examine the differences in means compared with the Reference group

exposure until the year 2008, and we are planning to update this data for future years when the relevant monitoring data will be available (for $\mathrm{PM}_{10}, \mathrm{NO}_{2}$, and specific components). In addition, exposure to other, 'criteria' air pollutants such as $\mathrm{SO}_{2}$ and $\mathrm{CO}$ could be estimated in the future using the same modelling procedure.
Assigning exposures based on the home address at time of delivery may introduce exposure misclassification as a number of women change their address during pregnancy [36], and are thus exposed to different levels of air pollution. We obtained full residential history of the participants, which showed that $26 \%$ of the women

Table 4 Maternal air pollution exposure during total pregnancy according to infant characteristics

\begin{tabular}{|c|c|c|c|}
\hline & $\mathrm{N}$ & $\mathrm{PM}_{10}$ exposure $\left(\mu \mathrm{g} / \mathrm{m}^{3}\right)$ Mean (SD) & $\mathrm{NO}_{2}$ exposure $\left(\mu \mathrm{g} / \mathrm{m}^{3}\right)$ Mean (SD) \\
\hline \multicolumn{4}{|l|}{ Child characteristics } \\
\hline \multicolumn{4}{|l|}{ Gestational age at birth } \\
\hline$<37$ weeks & 463 & $30.4(3.3)$ & $40.0(4.5)$ \\
\hline 37-42 weeks (Reference) & 6871 & $30.2(3.1)$ & $39.7(4.2)$ \\
\hline$<42$ weeks & 556 & 30.1 (3.3) & $39.7(4.1)$ \\
\hline \multicolumn{4}{|l|}{ Birth weight } \\
\hline$<2500$ grams & 359 & $30.4(3.1)$ & $40.0(4.4)$ \\
\hline 2500-4500 grams (Reference) & 7194 & $30.2(3.2)$ & $39.7(4.2)$ \\
\hline$>4500$ grams & 337 & $30.0(3.2)$ & $39.6(4.3)$ \\
\hline \multicolumn{4}{|l|}{ Season of birth } \\
\hline Winter (Reference) & 1856 & $29.7(2.7)$ & $38.9(4.1)$ \\
\hline Spring & 1781 & $30.4(2.3)^{* *}$ & $41.0(3.8)^{* *}$ \\
\hline Summer & 2098 & $30.5(3.4) * *$ & $40.4(4.0) * *$ \\
\hline Fall & 2155 & $30.0(3.8)$ & $38.7(4.5)$ \\
\hline \multicolumn{4}{|l|}{ Year of birth } \\
\hline 2002 (Reference) & 696 & $33.6(1.7)$ & $39.6(3.5)$ \\
\hline 2003 & 2406 & $33.2(1.6)^{* *}$ & $41.9(3.9) * *$ \\
\hline 2004 & 2548 & $27.6(2.4) * *$ & $39.0(4.2) *$ \\
\hline 2005 & 2214 & $28.8(1.5) * *$ & $38.3(3.9) * *$ \\
\hline 2006 & 26 & $27.8(1.3) * *$ & $36.8(4.1) *$ \\
\hline
\end{tabular}

** $P<0.01$

* $P<0.05$

Values are mean $\mathrm{PM}_{10}$ and $\mathrm{NO}_{2}$ exposure levels for the total pregnancy period. $P$-values are based on One-way ANOVA followed by Bonferroni's post hoc comparison tests to examine the differences in means compared with the Reference group 
moved at least once in the period between conception and the first year postnatally. Air pollution exposure estimates were assessed for the different prenatal and postnatal addresses. There can still be non-differential misclassification of air pollution exposure, since exposure levels were estimated at the home address, and people do not spend all of their time at home. Indoor, occupational, or commuting sources of air pollution have not been captured in our modelling procedures. The extent of the possible misclassification may be minor in this specific population, as pregnant women are likely to spend more time at home than non-pregnant individuals, especially in the last stage of pregnancy [37].

There is increasing awareness of the importance to incorporate information on noise exposure in studies on traffic-related air pollution exposure and health [10-13]. Thus far, few studies have included both air pollution and noise when investigating health outcomes [10,38-40]. In our previous studies on air pollution and pregnancy outcomes, we included information on noise exposure, in order to adjust for its potential confounding effect $[18,19]$.

\section{Conclusions}

Detailed air pollution exposure levels are available for mothers, fathers, and children in the Generation $\mathrm{R}$ Study and efforts are ongoing to update these exposures. The individual exposure estimates can be used in further epidemiological studies focused on the effects of prenatal and postnatal air pollution exposure on various health outcomes in mothers and children, including reproductive outcomes, growth and development, cognitive function, respiratory function, and cardiovascular outcomes. The combination with other detailed data (noise levels, biomarkers, and genetics) enables in-depth investigations and identification of critical windows of exposure.

\section{Abbreviations}

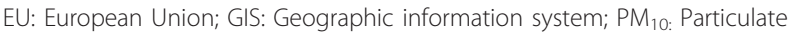
matter with an aerodynamic diameter $<10 \mu \mathrm{m} ; \mathrm{PM}_{2.5}$ : Particulate matter with an aerodynamic diameter $<2.5 \mu \mathrm{m} ; \mathrm{NO}_{2}$ : Nitrogen dioxide; $\mathrm{CO}$ : Carbon monoxide; $\mathrm{O}_{3}$ : Ozone; $\mathrm{SO}_{2}$ : Sulfur dioxide.

\footnotetext{
Acknowledgements

The Generation R Study is conducted by the Erasmus Medical Center Rotterdam in close collaboration with the School of Law and Faculty of Social Sciences of the Erasmus University Rotterdam, the Municipal Health Service Rotterdam area, the Rotterdam Homecare Foundation and the Stichting Trombosedienst \& Artsenlaboratorium Rijnmond (STAR-MDC), Rotterdam. We gratefully acknowledge the contribution of participating mothers and children, general practitioners, hospitals, midwives and pharmacies in Rotterdam. We also thank Henk Vos, Reinier Sterkenburg, and Han Zhou from TNO Urban Environment and Safety for exposure assessment, data linkage and providing air pollution maps, and the DCMR Environmental Protection Agency Rijnmond (DCMR) for kindly supplying data. The general design of the Generation $R$ Study is made possible by
}

financial support from the Erasmus Medical Center Rotterdam, the Erasmus University Rotterdam, the Netherlands Organization for Health Research and Development (ZonMw), the Netherlands Organisation for Scientific Research (NWO), the Ministry of Health, Welfare and Sport, and the Ministry of Youth and Families. Dr. Jaddoe reports receipt of funding from the Netherlands Organization for Health Research and Development (ZonMw 90700303, 916.10159). TNO received funding from The Netherlands Ministry of Infrastructure and the Environment (VROM) to support exposure assessment.

\section{Author details}

${ }^{1}$ The Generation R Study Group, Erasmus Medical Center, Rotterdam, The Netherlands. ${ }^{2}$ Urban Environment and Safety, TNO, Utrecht, The Netherlands. ${ }^{3}$ Department of Epidemiology, Erasmus Medical Center, Rotterdam, The Netherlands. ${ }^{4}$ Department of Paediatrics, Erasmus Medical Center, Rotterdam, The Netherlands.

\section{Authors' contributions}

All authors have made substantial contribution to this study and to the writing and editing of the manuscript. Additional contributions are as follows: EHH was involved in the planning of the study, data collection, descriptive analyses, and interpretation of data, and drafted the manuscript; FHP, WWJ and YK contributed to the design of the study, supervision, interpretation of data and critical review of the manuscript; SWR, PYJZ, and EWM designed the exposure assessment and performed exposure calculations; AH conceptionalised the Generation R study and participated in its design and conduction; HMEM contributed to the design of the study and had critical input. All authors read and approved the final manuscript.

\section{Competing interests}

The authors declare that they have no competing interests.

Received: 9 September 2011 Accepted: 22 February 2012 Published: 22 February 2012

\section{References}

1. Pope CA, Dockery DW: Health effects of fine particulate air pollution: lines that connect. J Air Waste Manag Assoc 2006, 56:709-742.

2. Brook RD, Rajagopalan S, Pope CA, Brook JR, Bhatnagar A, Diez-Roux AV, Holguin F, Hong Y, Luepker RV, Mittleman MA, et al: Particulate matter air pollution and cardiovascular disease: An update to the scientific statement from the American Heart Association. Circulation 2010, 121:2331-2378.

3. Kampa M, Castanas E: Human health effects of air pollution. Environ Pollut 2008, 151:362-367.

4. Sun Q, Hong X, Wold LE: Cardiovascular effects of ambient particulate air pollution exposure. Circulation 2010, 121:2755-2765.

5. Wang L, Pinkerton KE: Air pollutant effects on fetal and early postnatal development. Birth Defects Res C Embryo Today 2007, 81:144-154.

6. Ritz B, Wilhelm M: Ambient air pollution and adverse birth outcomes: methodologic issues in an emerging field. Basic Clin Pharmacol Toxicol 2008, 102:182-190.

7. Bonzini M, Carugno M, Grillo P, Mensi C, Bertazzi PA, Pesatori AC: Impact of ambient air pollution on birth outcomes: systematic review of the current evidences. Med Lav 2010, 101:341-363.

8. Shah PS, Balkhair T, Knowledge Synthesis Group on Determinants of Preterm and LBW births: Air pollution and birth outcomes: a systematic review. Environ Int 2011, 37:498-516.

9. Slama R, Darrow L, Parker J, Woodruff TJ, Strickland M, Nieuwenhuijsen M, Glinianaia S, Hoggatt KJ, Kannan S, Hurley F, et al: Meeting report: atmospheric pollution and human reproduction. Environ Health Perspect 2008, 116:791-798

10. De-Kluizenaar Y, Gansevoort RT, Miedema HM, De-Jong PE: Hypertension and road traffic noise exposure. J Occup Environ Med 2007, 49:484-492.

11. Allen RW, Davies H, Cohen MA, Mallach G, Kaufman JD, Adar SD: The spatial relationship between traffic-generated air pollution and noise in 2 US cities. Environ Res 2009, 109:334-342.

12. Davies HW, Vlaanderen JJ, Henderson SB, Brauer M: Correlation between co-exposures to noise and air pollution from traffic sources. Occup Environ Med 2009, 66:347-350.

13. Foraster M, Deltell A, Basagana X, Medina-Ramon M, Aguilera I, Bouso L, Grau M, Phuleria HC, Rivera M, Slama R, et al: Local determinants of road 
traffic noise levels versus determinants of air pollution levels in a Mediterranean city. Environ Res 2011, 111:177-183.

14. Jerrett M, Arain A, Kanaroglou P, Beckerman B, Potoglou D, Sahsuvaroglu T, Morrison J, Giovis C: A review and evaluation of intraurban air pollution exposure models. J Expo Anal Environ Epidemiol 2005, 15:185-204.

15. Bellander T, Berglind N, Gustavsson P, Jonson T, Nyberg F, Pershagen G, Jarup L: Using geographic information systems to assess individual historical exposure to air pollution from traffic and house heating in Stockholm. Environ Health Perspect 2001, 109:633-639.

16. Jaddoe WW, Van-Duijn CM, Van der-Heijden AJ, Mackenbach JP, Moll HA, Steegers EA, Tiemeier H, Uitterlinden AG, Verhulst FC, Hofman A: The Generation R Study: design and cohort update 2010. Eur J Epidemiol 2010, 25:823-841.

17. Jaddoe WW, Bakker R, Van-Duijn CM, Van der-Heijden AJ, Lindemans J, Mackenbach JP, Moll HA, Steegers EA, Tiemeier H, Uitterlinden AG, et al: The Generation R Study Biobank: a resource for epidemiological studies in children and their parents. Eur J Epidemiol 2007, 22:917-923.

18. Van den-Hooven EH, De-Kluizenaar Y, Pierik FH, Hofman A, VanRatingen SW, Zandveld PYJ, Mackenbach JP, Steegers EAP, Miedema HME, Jaddoe $\mathrm{WW}$ : Air pollution, blood pressure, and the risk of hypertensive complications during pregnancy: the Generation R Study. Hypertension 2011, 57:406-412.

19. Van den-Hooven EH, Pierik FH, de-Kluizenaar Y, Willemsen SP, Hofman A, Van-Ratingen SW, Zandveld PYJ, Mackenbach JP, Steegers EAP, Miedema HME, Jaddoe $\mathrm{WW}$ : Air pollution exposure during pregnancy, ultrasound measures of fetal growth, and adverse birth outcomes: a prospective cohort study. Environ Health Perspect 2012, 120:150-156.

20. Netherlands Ministry of Infrastructure and the Environment: Air Quality Decree 2007 (Regeling beoordeling Luchtkwaliteit 2007). Staatscourant 2007, Available: http://wetten.overheid.nl/BWBR0022817/ [accessed 12 September 2010].

21. Beelen R, Voogt M, Duyzer J, Zandveld P, Hoek G: Comparison of the performances of land use regression modelling and dispersion modelling in estimating small-scale variations in long-term air pollution concentrations in a Dutch urban area. Atmospheric Environment 2010, 44:4614-4621.

22. Keuken M, Zandveld P, Van den-Elshout S, Janssen NAH, Hoek G: Air quality and health impact of PM10 and EC in the city of Rotterdam, the Netherlands in 1985-2008. Atmospheric Environment 2011, 45:5294-5301.

23. De-Kluizenaar $Y$, Janssen SA, Van-Lenthe FJ, Miedema HM, Mackenbach JP. Long-term road traffic noise exposure is associated with an increase in morning tiredness. J Acoust Soc Am 2009, 126:626-633.

24. European Commission: Directive 2008/50/EC of the European Parliament and of the Council of 21 May 2008 on ambient air quality and cleaner air for Europe. 2008, Available: http://eur-lex.europa.eu/LexUriServ/ LexUriServ.do?uri=OJ:L:2008:152:0001:0044:EN:PDF.

25. World Health Organization: Health aspects of air pollution. Results from the WHO project "Systematic review of health aspects of air pollution in Europe" 2004, Available: http://www.euro.who.int/_data/assets/pdf_file/0003/74730/ E83080.pdf.

26. Fischer PH, Hoek G, Van-Reeuwijk H, Briggs DJ, Lebret E, Van-Wijnen JH, Kingham S, Elliott PE: Traffic-related differences in outdoor and indoor concentrations of particles and volatile organic compounds in Amsterdam. Atmospheric Environment 2000, 34:3713-3722.

27. Lewne M, Cyrys J, Meliefste K, Hoek G, Brauer M, Fischer P, Gehring U, Heinrich J, Brunekreef B, Bellander T: Spatial variation in nitrogen dioxide in three European areas. Sci Total Environ 2004, 332:217-230.

28. Van den-Hooven EH, de-Kluizenaar $Y$, Pierik FH, Hofman A, VanRatingen SW, Zandveld PYJ, Lindemans J, Russcher H, Steegers EAP, Miedema HME, Jaddoe WW: Chronic air pollution exposure during pregnancy and maternal and fetal C-reactive protein levels. The Generation R Study. Environ Health Perspect 2012, doi:10.1289/ehp.1104345.

29. Aguilera I, Sunyer J, Fernandez-Patier R, Hoek G, Aguirre-Alfaro A, Meliefste K, Bomboi-Mingarro MT, Nieuwenhuijsen MJ, Herce-Garraleta D, Brunekreef B: Estimation of outdoor $\mathrm{NO}(\mathrm{x}), \mathrm{NO}(2)$, and BTEX exposure in a cohort of pregnant women using land use regression modeling. Environ Sci Technol 2008, 42:815-821.

30. Slama R, Morgenstern V, Cyrys J, Zutavern A, Herbarth O, Wichmann HE, Heinrich J: Traffic-related atmospheric pollutants levels during pregnancy and offspring's term birth weight: a study relying on a land-use regression exposure model. Environ Health Perspect 2007, 115:1283-1292.
31. Iniguez C, Ballester F, Estarlich M, Llop S, Fernandez-Patier R, AguirreAlfaro A, Esplugues A, Inma Study group V: Estimation of personal NO2 exposure in a cohort of pregnant women. Sci Total Environ 2009, 407:6093-6099.

32. Gehring U, Wijga AH, Fischer P, De-Jongste JC, Kerkhof M, Koppelman GH, Smit HA, Brunekreef B: Traffic-related air pollution, preterm birth and term birth weight in the PIAMA birth cohort study. Environ Res 2011, 111:125-135.

33. Peters A: Particulate matter and heart disease: evidence from epidemiological studies. Toxicol Appl Pharmacol 2005, 207:477-482.

34. Kannan S, Misra DP, Dvonch JT, Krishnakumar A: Exposures to airborne particulate matter and adverse perinatal outcomes: a biologically plausible mechanistic framework for exploring potential effect modification by nutrition. Environ Health Perspect 2006, 114:1636-1642.

35. World Health Organization: Air quality guidelines. Global update 2005 Particulate matter, ozone, nitrogen dioxide and sulphur dioxide; 2006 Available: http://whqlibdoc.who.int/hq/2006/ WHO SDE PHE_OEH 06.02 eng.pdf.

36. Fell DB, Dodds $\mathrm{L}$, King WD: Residential mobility during pregnancy. Paediatr Perinat Epidemiol 2004, 18:408-414.

37. Nethery $E$, Brauer $M$, Janssen P: Time-activity patterns of pregnant women and changes during the course of pregnancy. J Expo Sci Environ Epidemiol 2009, 19:317-324.

38. Tobias A, Diaz J, Saez M, Alberdi JC: Use of poisson regression and boxjenkins models to evaluate the short-term effects of environmental noise levels on daily emergency admissions in Madrid, Spain. Eur $J$ Epidemiol 2001, 17:765-771.

39. Beelen R, Hoek G, Houthuijs D, Van den-Brandt PA, Goldbohm RA, Fischer $P$, Schouten $L$, Armstrong B, Brunekreef $B$ : The joint association of air pollution and noise from road traffic with cardiovascular mortality in a cohort study. Occup Environ Med 2009, 66(4):243-50.

40. Selander J, Nilsson ME, Bluhm G, Rosenlund M, Lindqvist M, Nise G, Pershagen G: Long-term exposure to road traffic noise and myocardial infarction. Epidemiology 2009, 20:272-279.

doi:10.1186/1476-069X-11-9

Cite this article as: Van den Hooven et al:: Air pollution exposure estimation using dispersion modelling and continuous monitoring data in a prospective birth cohort study in the Netherlands. Environmental Health 2012 11:9.

\section{Submit your next manuscript to BioMed Central and take full advantage of:}

- Convenient online submission

- Thorough peer review

- No space constraints or color figure charges

- Immediate publication on acceptance

- Inclusion in PubMed, CAS, Scopus and Google Scholar

- Research which is freely available for redistribution

Submit your manuscript at www.biomedcentral.com/submit
C Biomed Central 